\title{
A fiber-coupled laser hygrometer for airborne total water measurement
}

\author{
S. W. Dorsi ${ }^{1}$, L. E. Kalnajs ${ }^{1}$, D. W. Toohey ${ }^{2}$, and L. M. Avallone ${ }^{1,2}$ \\ ${ }^{1}$ Laboratory for Atmospheric and Space Physics, University of Colorado, Boulder, Colorado, USA \\ ${ }^{2}$ Department of Atmospheric and Oceanic Sciences, University of Colorado, Boulder, Colorado, USA
}

Correspondence to: S. W. Dorsi (dorsi@colorado.edu)

Received: 24 June 2013 - Published in Atmos. Meas. Tech. Discuss.: 12 August 2013

Revised: 6 December 2013 - Accepted: 11 December 2013 - Published: 27 January 2014

\begin{abstract}
The second-generation University of Colorado closed-path tunable-diode laser hygrometer (CLH-2) is an instrument for the airborne in situ measurement of total water content - the sum of vapor-, liquid- and ice-phase water in clouds. This compact instrument has been flown on the NSF/NCAR Gulfstream- $\mathrm{V}$ aircraft in an underwing canister. It operates autonomously and uses fiber-coupled optics to eliminate the need for a supply of dry compressed gas. In operation, sample air is ingested into a forward-facing subisokinetic inlet; this sampling configuration results in particle concentrations that are enhanced relative to ambient and causes greater instrument sensitivity to condensed water particles. Heaters within the inlet vaporize the ingested water particles, and the resulting augmented water vapor mixing ratio is measured by absorption of near-infrared light in a single-pass optical cell. The condensed water content is then determined by subtracting the ambient water vapor content from the total and by accounting for the inertial enhancement of particles into the sampling inlet. The CLH-2 is calibrated in the laboratory over a range of pressures and water vapor mixing ratios; the uncertainty in CLH-2 condensed water retrievals is estimated to be $14.3 \%$ to $16.1 \%$ (1$\sigma)$. A vapor-only laboratory intercomparison with the firstgeneration University of Colorado closed-path tunable-diode laser hygrometer (CLH) shows agreement within the 2- $\sigma$ uncertainty bounds of both instruments.
\end{abstract}

\section{Introduction}

Water is ubiquitous in the Earth's atmosphere and plays a primary role in the planet's climate and weather. The fact that conditions on Earth support three phases of water - liquid, ice and vapor - is a defining characteristic of the planet that affects all Earth systems. Water vapor is the dominant greenhouse gas in the Earth's atmosphere and also amplifies existing temperature changes through feedback processes (Held and Soden, 2000). The transport of latent heat by water vapor is fundamental to convection and weather processes, and the redistribution of water through evaporation and precipitation is a major factor in shaping terrestrial biomes. In addition, both liquid-water and ice clouds have a profound effect on the radiative budget of the atmosphere (Liou, 1992) through their interaction with solar visible and terrestrial infrared radiation. While the global mean net radiative effect of clouds is approximately $-20 \mathrm{~W} \mathrm{~m}^{-2}$, the local magnitude of cloud radiative forcing varies across the planet and can be significantly greater (Allan, 2011).

The importance of cloud processes is not matched by commensurate scientific knowledge. While the net radiative effect of clouds is known on a planetary scale, the sign of the net cloud feedback from a change in the Earth's temperature is not (Stephens, 2005). Accurate measurement of some crucial cloud microphysical properties continues to present challenges. In particular, the measurement of a single phase of water, when multiple phases are present, remains an elusive goal (Baumgardner et al., 2012). All existing measurement techniques are imperfect, with most exhibiting sensitivities to more than one phase of water. For example, closedpath systems designed to sample vapor can be contaminated by evaporation of ingested particulates, and hot-wire sensors often show a response to ice particles in addition to the liquid drops they are designed to measure (Cober et al., 2001; Korolev et al., 2003). The central problem - that measuring water concentration in clouds often results in observations that represent an ambiguous combination of phases - can be 
avoided by instead measuring total water content - the sum of water mass contained in solid, liquid and vapor forms ${ }^{1}$. Despite its potential utility in cloud water measurement, total water instruments are not always used during field studies. Logistical constraints, such as size, weight, power consumption and the need for compressed gases, may limit the deployability of some existing total water hygrometers. In this paper, we describe the design and characteristics of a new total water instrument that operates autonomously, does not require compressed gas and fits in a standard aircraft underwing canister.

\section{Instrument design}

The second-generation University of Colorado closed-path tunable-diode laser hygrometer (CLH-2) is a total water instrument based on the measurement principles of the firstgeneration instrument, or CLH (Hallar et al., 2004; Davis et al., 2007b). The principal innovations that distinguish the CLH-2 from its predecessor are the former's compact and standardized form factor, redesigned electronics and optical system, operation without consumable gas, and Ethernet control.

\footnotetext{
${ }^{1}$ The term "total water content" is used with two conflicting meanings in the atmospheric instrumentation literature: it is used either to designate the condensed water content (ice + liquid water phases only) or to designate the water content in these condensed phases plus that in water vapor. For example, the hot-wire Nevzorov probe has a sensor with conical geometry designed to measure the liquid and/or ice water content of clouds (Korolev et al., 1998); the measurements made with this sensor are often referred to as "total water content" (e.g., Cober et al., 2001; Strapp et al., 2003; Boudala et al., 2004, Baumgardner et al., 2011), although these measurements by design exclude water vapor. Alternately, authors working with evaporative hygrometers refer to the measured sum of condensed water plus ambient water vapor as the "total water" (e.g., Brown and Francis, 1995; Wood and Field, 2000; Davis et al., 2007b). Also complicating interpretation of the literature is the diversity of terms used to denote the sum of ice plus liquid water excluding water vapor; these terms include "condensed water content" (e.g., Twohy et al., 1997), "total condensed water content" (e.g., Hogan et al., 2002), "cloud water content" (Strom and Heintzenberg, 1994), and "total condensate content" (Gultepe and Isaac, 1997). Because the term "total" in its general usage is suggestive of a complete sum, we choose to use the phrase "total water content" (TWC; $\mathrm{g} \mathrm{m}^{-3}$ ) to refer to the mass concentration of water in all phases, including vapor. We then use the phrase "condensed water content" (CWC; $\mathrm{g} \mathrm{m}^{-3}$ ) to refer to the sum of ice water plus liquid water. This phase-specific terminology can be expressed as a function of the liquid water content ( $\mathrm{LWC} ; \mathrm{g} \mathrm{m}^{-3}$ ), ice water content (IWC; $\mathrm{g} \mathrm{m}^{-3}$ ) and water vapor content $\left(\mathrm{W} ; \mathrm{g} \mathrm{m}^{-3}\right)$ :
}

$\mathrm{TWC}=\mathrm{IWC}+\mathrm{LWC}+\mathrm{W}$

$\mathrm{CWC}=\mathrm{IWC}+\mathrm{LWC}$

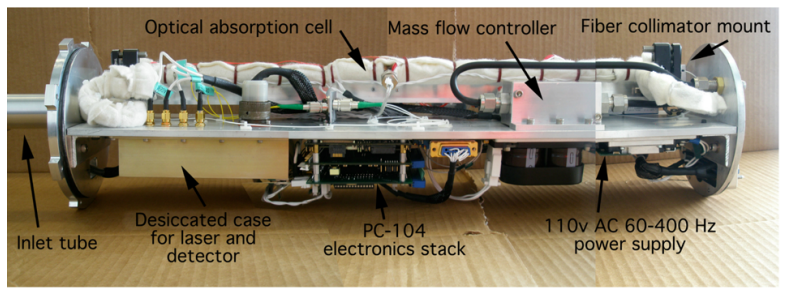

a.
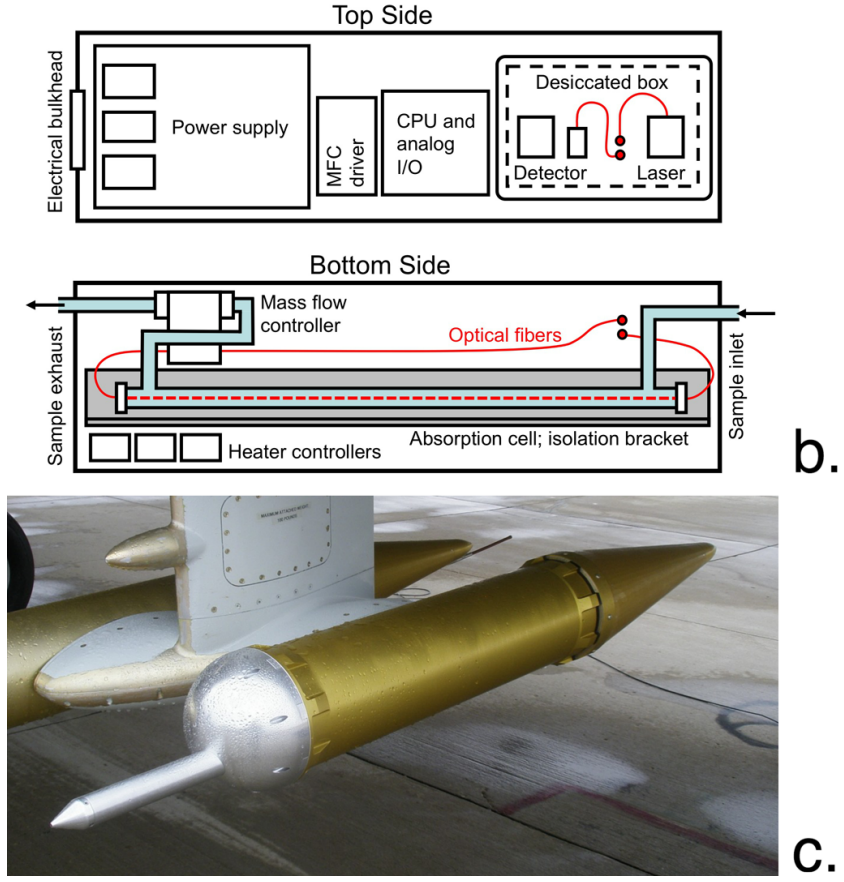

Fig. 1. Image (a) and schematic diagram (b) showing layout of primary CLH-2 components on the top and bottom sides of a central structural plate, and image of the canister-mounted CLH-2 with integral forward-facing inlet (c).

The CLH-2 (Fig. 1) uses tunable diode laser spectroscopy to measure the TWC in an air parcel, including the ambient water vapor and that contributed from condensed water particles as they evaporate during transit through an integral heated inlet. Inside a temperature-regulated cell, a photodetector measures light transmission through the sample gas as a laser performs a wavelength scan over a water vapor absorption feature. The absorption spectrum is converted to a water vapor mixing ratio based on laboratory calibrations and temperature and pressure measured in the absorption cell.

Water vapor is measured in a $53.3 \mathrm{~cm}$-long, closed-path cell with a single-pass optical path. The cell is composed of type 303 stainless steel tubing $(11.0 \mathrm{~mm}$ internal diameter) and is temperature-regulated to $40{ }^{\circ} \mathrm{C}\left( \pm 0.1^{\circ} \mathrm{C}\right.$ deadband, $\pm 1.0^{\circ} \mathrm{C}$ accuracy) using a Minco CT325 temperature controller driving thermofoil heaters on the cell walls. The entire sample flow path upstream of the absorption cell is also heated to $40^{\circ} \mathrm{C}$ using thermofoil heaters driven by Minco CT325 controllers. A mass-flow controller (Tylan FC2901) located downstream of the absorption cell regulates 
the flow rate of the sample air; for a nominal flow rate of $2 \operatorname{std} \mathrm{L} \mathrm{min}^{-1}$, the sample air in the cell is exchanged every $1.5 \mathrm{~s}(0.30 \mathrm{~s})$ at $1000 \mathrm{hPa}(200 \mathrm{hPa})$.

The narrow-band light source is a $10 \mathrm{~mW}$, indium gallium arsenide phosphide (InGaAsP), direct-feedback diode laser (NTT Electronics) with wavelength center at $1368.6 \mathrm{~nm}$ $\left(7306.7 \mathrm{~cm}^{-1}\right)$ and full-width at half-maximum (FWHM) of $0.4 \mathrm{~nm}$. The detector is a broadband indium gallium arsenide (InGaAs) photodiode (ThorLabs FGA04) operated in photovoltaic (zero bias) mode. The temperatures of the laser diode and detector packages are regulated using pulse-widthmodulated thermoelectric coolers driven by a custom-built control circuit. A second photodiode mounted directly within the laser diode package continuously monitors laser power. The detector signal is amplified by a custom-built electronic circuit that is shielded from electromagnetic interference and co-located with the detector. Optical fibers (Corning SMF28e single-mode) connect the laser source and photodetector with aligned gradient-index (GRIN) collimators (ThorLabs 501310-APC) at opposite ends of the absorption cell. These optical fibers have a mode field diameter of $9.3 \mu \mathrm{m}$ and transmission losses of less than $0.5 \mathrm{~dB} \mathrm{~km}^{-1}$. Angled physicalcontact fiber connectors maximize return loss and protect the laser from reflected energy.

To avoid spurious signals, optical paths outside of the absorption cell are designed to minimize contamination by water vapor. This is achieved in part by the use of GRIN lenses, which focus light by an internal variation in the index of refraction of the single monolithic lens body, and by the direct fusing of these lenses to the optical fibers, thus eliminating the air spaces present in common multi-lens focusing systems (such as aspheric collimators). Additionally, the use of optical fibers allows the laser source and detector to be colocated in a compact, sealed metal box that is desiccated to reduce water vapor concentration within optical paths in the laser and detector packages. These optical paths total $6 \mathrm{~mm}$, which represents about $1 \%$ of the primary absorption cell optical path. Water vapor within the metal case is maintained below $5 \mu \mathrm{mol} \mathrm{mol}^{-1}$ by a calcium sulfate (gypsum) desiccant. At the detection limit of $750 \mu \mathrm{mol} \mathrm{mol}^{-1}$, light absorption from the water vapor contained in the laser and detector package optical paths is estimated to represent $0.005 \%$ of the total absorption signal. The fractional contribution to the total signal is further reduced at larger sample mixing ratios. The passive desiccation of these optical components and the use of optical fibers eliminate the need for constant purging of these dead volumes with dry gas $\left(\mathrm{N}_{2}\right.$ or air), significantly reducing the size, weight and complexity of the instrument package.

The instrument is controlled by an onboard PC/104 single board computer (Diamond Systems Aurora) with a $1.6 \mathrm{GHz}$ Intel Atom Z530 processor and 2 GB RAM. The operating code and data are stored on a hard-mounted USB flashdisk. The computer is passively cooled by conduction through a bottom-mounted heat spreader to the primary instrument baseplate. A 16-bit analog input/output (I/O) board (Diamond Systems DMM-32-DX-AT) provides basic data acquisition capabilities. A custom circuit board that conforms to the PC/104 form factor handles power management, laser drive and protection, signal processing, and temperature regulation of optical components. A first-in-first-out (FIFO) memory array produces the periodic function that is converted by a 12-bit digital-to-analog converter (DAC) to the voltage necessary to drive wavelength scans. The instrument operating code is in the programming language $\mathrm{C}$ and is run under a command-line Linux operating system (Ubuntu 10.04 Lucid Lynx). An Ethernet connection enables remote monitoring, software modification, data download, and time synchronization over Network Time Protocol (NTP).

Pressure is measured at the midpoint of the absorption cell by a Motorola MPXM2102 silicon piezoresistive sensor, and temperature is measured at the upstream and downstream ends of the cell by $10-\mathrm{k} \Omega$ platinum resistive thermal devices (RTDs). To improve reliability, shock resistance, and performance at low ambient temperatures, the cell and associated optical components are mounted on a rigid bracket that is suspended on rugged wire isolation mounts and temperatureregulated to $30^{\circ} \mathrm{C}$. The complete $\mathrm{CLH}-2$ package is contained within a standard 6-inch-diameter by 24 -inch-long scientific aircraft wing canister, known colloquially as a "PMS canister" (Droplet Measurement Technologies).

The laser drive current is modulated with a $20 \mathrm{~Hz}$ sawtooth pattern; this produces a corresponding variation in laser wavelength that ramps linearly over the water vapor absorption feature. An example scan appears in Fig. 2. The 512 discrete voltage steps generated by a 12-bit DAC are converted into a linear current variation by a custom laser drive circuit. The laser is powered down for a brief period during each scan, and the detector dark voltage that is measured is averaged and subtracted from the detector voltages observed during the scan. For each wavelength step, light transmission is calculated by dividing the observed detector output voltage by the baseline voltage that would be seen at the detector if there were no absorption. As illustrated in Fig. 2, this baseline voltage is estimated by fitting a 3rd-order polynomial to the observed scan ramp on either side of the absorption feature. The following paragraphs describe the processing of the resulting transmission spectrum to retrieve a water vapor mixing ratio.

The CLH-2 is optimized for the higher TWC of the lower troposphere and within convective clouds, so direct absorption detection is applied, rather than the typical secondharmonic spectroscopy that is used by some other TDLbased water instruments designed for drier environments. By using direct absorption only, the CLH-2 also benefits from the simplification of data analysis and does not require realtime modulation and de-modulation electronics (although the capability can be implemented for improved sensitivity in measurement of smaller CWCs). 


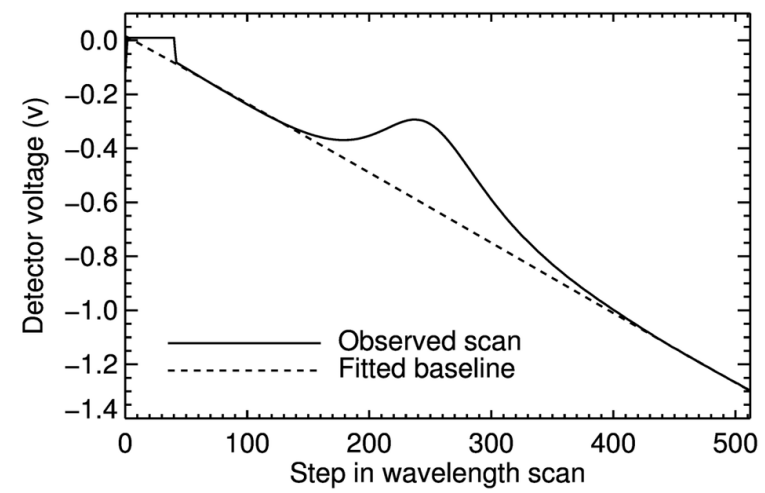

Fig. 2. Absorption spectrum as recorded by CLH-2, showing a single observed scan. This includes the dark voltage observations at steps 1 to 40, and the wavelength scan (steps 40 to 512) with the prominent absorption feature centered at about step 250. The fitted baseline provides an estimate of the detector output were no absorption to occur.

Observed spectral lines exhibit a finite width due to the combined effects of collision, Doppler and other broadening processes. Estimates of total absorption that use a measurement at line center require corrections for the effects of line broadening (Arroyo and Hanson, 1993). Instead, CLH-2 records transmission across the entire broadened absorption feature, and we integrate over wavelength to find the total energy absorbed. This reduces error due to uncertainty in the spectroscopic parameters or line-shape function. To estimate the improvement in the error budget that results from integrating over the absorption feature rather than measuring line-center absorption and modeling broadening, a Monte Carlo analysis was applied to a series of equations for the generation of a Voigt profile (Liou, 1992). Normally distributed (Gaussian) errors were introduced into the broadening parameters based on their specified uncertainty in HITRAN2004 (Rothman et al., 2005). The simulation shows the uncertainty in broadening to result in $0.9 \%$ error in the line-center magnitude. In total, the integration technique reduces uncertainty by $3.1 \%$ relative to the line-center absorption technique, including the error in the numerical solution used to generate a Voigt profile. Integration over the absorption feature also inherently averages out random highfrequency noise in laser output or the detector circuit, which is on the order of $1 \%$ of the absorption magnitude in this system.

The CLH-2, like its predecessor CLH, uses a forwardfacing, sub-isokinetic inlet (Fig. 1c), in which the velocity of the sample air at the point of entry into the inlet is less than that of the free stream. This design inertially concentrates particles into the inlet, thereby increasing the sensitivity to condensed water. As a result, the CLH-2 directly measures enhanced total water content (eTWC), that is, the sum of the ambient water vapor content and the CWC as enhanced by the sub-isokinetic sampling of water particles at

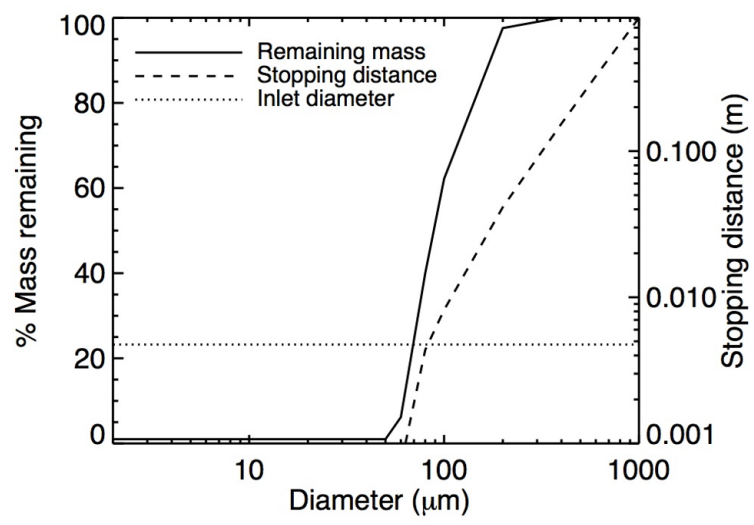

Fig. 3. Fraction of particle mass remaining after transit of heated $0.65 \mathrm{~m}$ inlet (left axis), and particle stopping distance (right axis), both as a function of particle size. Particles with stopping distance greater than the inlet diameter will impact on inlet walls at a $90^{\circ}$ bend.

the inlet (eCWC). However, for most applications, the CWC, corrected for the inlet particle enhancement, is desired. The derivation of CWC from eTWC has been described by Davis et al. (2007b) and Hallar et al. (2004), so it is summarized only briefly here. In determining CWC, an independent measurement of the ambient water vapor content is subtracted from the eTWC; the difference is the eCWC. The effect of sub-isokinetic sampling is removed by dividing eCWC by the particle sampling efficiency weighted by the particle mass distribution. The sampling efficiency curve is based on aspiration efficiency parameterizations or on computational fluid dynamics simulations (Davis et al., 2007b) unique to a specific instrument installation and flight conditions, and the mass distribution is estimated from independent observations of the particle size distribution from optical cloud probes.

Because of the chosen center wavelength and narrow line source, the CLH-2 is sensitive only to vapor-phase water. Based on the approach of Davis et al. (2007b), we use a Lagrangian model to simulate the heating and evaporation of spherical ice particles during transit from inlet entrance to absorption cell. Model results shown in Fig. 3 indicate that solid ice spheres of diameter less than $58 \mu \mathrm{m}$ will be fully vaporized during inlet transit. Because their stopping distance is greater than the diameter of the inlet tubing $(4.75 \mathrm{~mm})$, those particles larger than $88 \mu \mathrm{m}$ diameter will impact the inlet wall upon reaching a $90^{\circ}$ bend in the sample flow path. These impacted particles may shatter into more readily vaporized smaller fragments, or may adhere to the wall, increasing residence time. Solid ice spheres of diameter $58 \mu \mathrm{m}$ to $88 \mu \mathrm{m}$ may be incompletely vaporized, with nearly complete vaporization at $58 \mu \mathrm{m}$ and up to $50 \%$ of particle mass remaining at $88 \mu \mathrm{m}$ (Fig. 3). The magnitude of the resulting low bias in measured water mass will depend on the fraction of total condensed water mass contributed by particles in this size range. Although this model assumes that particles entering 
the inlet are solid ice spheres, actual cloud particles are often non-spherical (Magono and Lee, 1966) and thus exhibit a greater surface-area-to-mass ratio. As a result, this model will tend to overestimate vaporization time, so the calculated vaporized fractions likely represent a lower limit.

\section{Total water calibration procedure}

Because the CLH-2 measures total water content as a vaporphase mixture - the ambient water vapor content augmented by the vaporized content of sampled condensed water particles - it is calibrated using mixtures of a known water vapor mixing ratio (VMR) in high purity air. While other condensed water instruments have been successfully calibrated by introducing liquid water sprays (Strapp et al., 2003) or ice shavings (Korolev et al., 2013) into a wind tunnel and characterizing the resulting water concentration gradients, for an evaporative total water hygrometer such as the CLH-2, performing the calibration using a sample that includes only water vapor, that is, with the total water content equal to the water vapor content, simplifies the production of calibration mixtures.

In concept, observations of the direct absorption spectra over a water vapor absorption feature can be used to determine the water vapor mixing ratio without a laboratory calibration, because the measured absorption is related to the number density of water vapor by Beer's law. However, retrieving the water vapor number density from the direct absorption scans based on the spectral parameters introduces $5 \%$ to $10 \%$ uncertainty from the $\mathrm{H}_{2} \mathrm{O}$ absorption line strength (Rothman et al., 2005) and further uncertainty from determination of the scan wavelength scale, which can otherwise be an arbitrary abscissa, such as scan step or tuning current in mA (May and Webster, 1993). Furthermore, unquantified effects of the instrument electronics' response, such as non-linearity in the wavelength scale (Davis et al., 2007b), may introduce additional uncertainty. Instead, the CLH-2 water vapor retrieval algorithms are based on the results of a laboratory calibration.

The CLH-2 is calibrated using VMRs ranging from $\sim 600 \mathrm{~mol} \mathrm{~mol}^{-1}$ to $\sim 23000 \mu \mathrm{mol} \mathrm{mol}^{-1}$ and over pressures spanning $133 \mathrm{hPa}$ to $800 \mathrm{hPa}$. Absorption spectra are recorded by the CLH-2 and compared with VMRs that are produced by a Li-Cor 610 dewpoint generator and qualitatively diluted using high-accuracy flow controllers and a supply of dry gas. The temperature of the dewpoint generator condenser block is measured with a platinum RTD calibrated against National Institute of Standards and Technology (NIST)-traceable devices and methods; the expected dewpoint accuracy is $\pm 0.2^{\circ} \mathrm{C}$ (Li-Cor, 2004).

To produce calibration mixtures representing high eTWCs, the undiluted output of the dewpoint generator is used. Calibration mixtures with dewpoints $<0^{\circ} \mathrm{C}$ are produced by diluting the output of the Li-Cor 610 with ultra-high

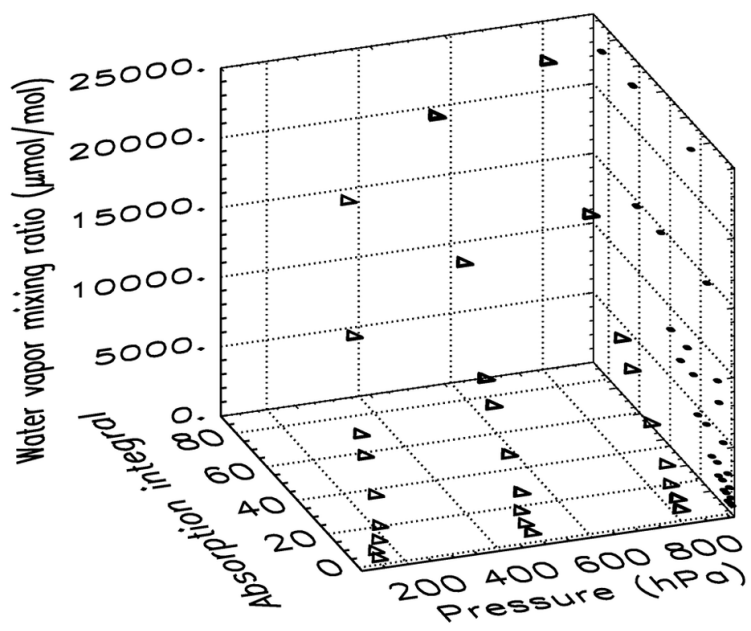

Fig. 4. Grid of calibration points, with VMR and pressure inputs from calibration setup and observed integral over absorption feature. Calibration points are projected onto the right-hand plot wall for clarity.

purity nitrogen (supplier specification $<1 \mu \mathrm{mol} \mathrm{mol}^{-1}$ water vapor). Mass flow controllers (MFCs) placed downstream of the dewpoint generator and the dry gas source are used to regulate this dilution ratio (Unit UFC 7300, $500 \mathrm{std} \mathrm{cm}^{3} \mathrm{~min}^{-1}$ for humid air; Unit UFC 1660, $10 \mathrm{std} \mathrm{L} \mathrm{min}^{-1}$ for dry gas). The humid-air and dry-gas MFCs are accurate to $1 \%$ and $2 \%$, respectively, based on calibrations of the rate of pressure change into a vessel of known volume. Upstream of the MFCs, the dewpoint generator and dry gas source are held at ambient pressure, while the gas pressure downstream of the MFCs varies over the calibration pressure range. Typically, calibrations are made at three dewpoint temperatures, with three different pressures being used at each dewpoint temperature. This process is repeated for three different dilution ratios, yielding a total of 27 independent calibration points.

For the calibrations presented here, a stable VMR was maintained for each point until the CLH-2 absorption feature strength reached a constant value $(40 \mathrm{~min})$; absorption spectra were then recorded at multiple pressures for approximately $10 \mathrm{~min}$ each. The equilibration time is necessary for the dewpoint generator condenser block temperature to stabilize; the response time of the CLH-2 instrument to rapid changes in water concentration during cloud ingress and egress indicates that the response time of the instrument is typically less than $1 \mathrm{~s}$. For each spectrum, the area of the broadened absorption feature is found by integrating over wavelength. The resulting grid of absorption integrals at pressure and VMR combinations is shown in Fig. 4. A rational function is fitted to this grid of calibration points, and this function is evaluated at an observed pressure and absorption integral to retrieve VMR values in operation. 


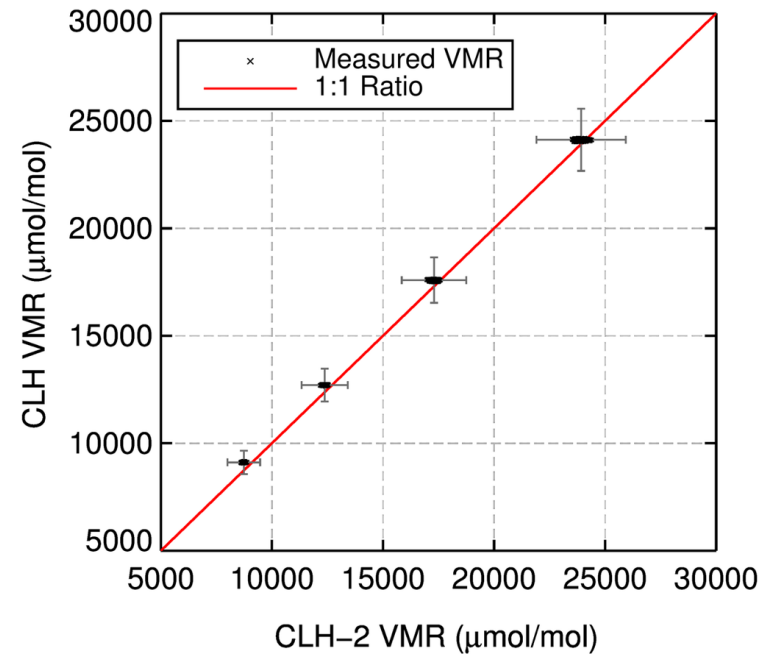

Fig. 5. Comparison of water vapor mixing ratios measured by CLH and CLH-2 instruments for the same calibration mixtures generated in a laboratory setup as described in the text. Error bars, which represent the 2- $\sigma$ VMR measurement uncertainty for each instrument, are centered at the population mean for each setpoint.

As an independent check on the accuracy of CLH-2, a laboratory comparison was performed with the first-generation $\mathrm{CLH}$, an instrument that itself has been previously compared (Davis et al., 2007a) with multiple total water instruments, including the Harvard University Lyman- $\alpha$ total water photofragment-fluorescence hygrometer (Weinstock et al., 2006) and the Droplet Measurement Technologies Cloud Spectrometer and Impactor (Twohy et al., 1997). As in the calibration, this laboratory intercomparison was performed using vapor-only mixtures: the undiluted output of the dewpoint generator was split in parallel and passed through the CLH and CLH-2 at atmospheric pressure $(843 \mathrm{hPa})$. Data were collected simultaneously with both instruments for $\sim 30 \mathrm{~min}$ at each of four mixing ratios ranging from $\sim 9000 \mathrm{\mu mol} \mathrm{mol}^{-1}$ to $\sim 24500 \mu \mathrm{mol} \mathrm{mol}^{-1}$ (Fig. 5). There was a high degree of correlation between the two measurements, with agreement to $1.1 \%$ (the slope of CLH VMR to CLH-2 VMR is 0.989 with $r^{2}=0.9998$ and $n=1513$ ), well within the combined 2- $\sigma$ uncertainty bounds of the two instruments.

\section{Estimated error}

Overall uncertainty in the CWC for CLH-2 observations includes uncertainties in laboratory calibrations and in the derivation of CWC from the observed eTWC. Here, we estimate the overall uncertainty by independently estimating the magnitude of these two error sources, first, by summing uncertainties for the composition of the calibration gas, and second, by considering the errors in the derivation of CWC from eTWC.

\subsection{CLH-2 VMR measurement uncertainties}

The accuracy of the CLH-2 measurement is limited by the uncertainty of the calibration mixtures described in Sect. 3. We estimate this uncertainty by summing the independent measurement errors from components of the calibration system. The uncertainty we quote for the undiluted output from the dewpoint generator is the manufacturer specification of $\pm 0.2^{\circ} \mathrm{C}$ (Li-Cor, 2004). The quoted error for the MFCs is the observed root-mean-square deviation (RMSD) of the observed flow rates through the MFCs from the fitted calibration line. Calibration of cell temperature RTDs is performed inside a thermal chamber by comparison with a NIST-traceable thermometer (Dostmann P600). Seven calibration temperatures, recorded over the range $+0^{\circ} \mathrm{C}$ to $+50^{\circ} \mathrm{C}$, are fitted to a calibration function that has an RMSD of less than $0.3 \%$ from the observations. The manufacturer of the pressure sensor specifies an accuracy of $1.3 \%$, and we observe the RMSD from linearity to be less than $0.5 \%$ over the pressure range $133 \mathrm{hPa}$ to $800 \mathrm{hPa}$.

The total uncertainty in the water vapor content of the calibration gas is found by quadratically summing these error sources, all of which contribute linearly to the total error. This CLH-2 water vapor calibration uncertainty (1- $\sigma$ error $=3.0 \%$ ) is similar to the CLH uncertainties (Davis et al., $2007 \mathrm{~b})$ for calibrations performed in $2003(1-\sigma$ error $=1 \%$ to $5 \%)$ and in $2005(1-\sigma$ error $=3.0 \%)$.

\subsection{CWC determination error}

When condensed water particles are present in the sample air, uncertainty in the sampling efficiency and uncertainty in the derivation of CWC from the eTWC will introduce additional sources of error. Although these errors will be specific to individual aircraft installations and flight conditions, here we present an overview of the relevant uncertainties and their expected magnitudes.

Before applying a sampling efficiency correction, the background water vapor content is removed from the enhanced TWC. Measurement error from the particular hygrometer used to measure water vapor content during a deployment will be introduced into the calculated value for enhanced CWC. For example, the 1- $\sigma$ error in airborne measurements of water vapor content are $3.7 \%$ for the NASA Langley/Ames Diode Laser Hygrometer (Podolske et al., 2003 ) and $\sim 5 \%$ for the Vertical Cavity Surface Emitting Laser Hygrometer (Zondlo et al., 2010).

The sampling efficiency correction addresses differences in particle concentrations between the air parcel to be sampled and the sample that enters the inlet. This correction is a function of particle size distribution, of isoaxial wind speed and of the inlet sampling angle with respect to the wind direction; errors in these deployment-specific measurements will affect the accuracy of the sampling efficiency correction. Davis et al. (2007b) estimate the uncertainty in particle 
Table 1. Estimated uncertainty in the CWC measurements made with the CLH-2, including uncertainty in the CLH-2 VMR calibration and in the determination of CWC using CLH-2 and other observations. All uncertainties quoted are 1- $\sigma$.

\begin{tabular}{lll}
\hline Contributing measurement & Uncertainty $(1-\sigma)$ & Reference or source \\
\hline Instrument calibration and retrieval & & \\
\hline Mass flow controller wet air & $1.0 \%$ & calibration RMSD \\
Mass flow controller dry air & $2.0 \%$ & calibration RMSD \\
manufacturer spec. + calibration RMSD \\
Cell pressure & $1.3 \%$ & calibration RMSD \\
Cell temperature & $0.3 \%$ & manufacturer spec. \\
Dewpoint generator VMR output & $1.5 \%$ & \\
Calibration VMR uncertainty & $3.0 \%$ & \\
\hline CWC determination & & Podolske et al. (2003), Zondlo et al. (2010) \\
\hline Water vapor content & $3.7 \%$ to $5 \%$ & Davis et al. (2007b) \\
Inlet flow rate & $7.5 \%$ to $10 \%$ & Khelif et al. (1999) \\
Aircraft airspeed & $1.0 \%$ & see text (Sect. 4.2) \\
Aircraft angle of attack & $>0.1 \%$ & Engblom and Ross (2003) \\
Particle tracking methodology & $10.0 \%$ & Davis et al. (2007b) \\
Particle size distribution & $5.0 \%$ & \\
CWC uncertainty & $14.0 \%$ to $15.8 \%$ & \\
\hline Total error in CWC & $14.3 \%$ to $16.1 \%$ & \\
\hline
\end{tabular}

size distribution to contribute $5 \%$ to the total CWC error. For large particles, whose enhancements in the inlet approach the inertial enhancement ratio (aircraft-relative free-air speed divided by inlet air speed), errors in the measured airspeed will create equal-magnitude errors in the corrected CWC. Based on an expected flight airspeed measurement accuracy of $\sim 1 \%$ (Khelif et al., 1999) and CLH-2 inlet airspeed uncertainty of $7.5 \%$ to $10 \%$ (Davis et al., 2007b), the resulting errors in CWC will be $7.6 \%$ to $10.0 \%$. Using a parameterization for sampling efficiency as a function of sampling angle (Durham and Lundgren, 1980), and assuming error in the measured aircraft attack angle of $0.06 \%$ (Khelif et al., 1999), the resulting error in CWC will be less than $0.1 \%$ at any particle size. Error in particle enhancements as determined through the Engblom and Ross (2003) particletracking methodology is estimated to be about $10 \%$.

\subsection{Total error accounting}

When no water particles are present, the 1- $\sigma$ error in the CLH-2 water vapor measurement is estimated to be $3.0 \%$. When water particles are present, the determination of CWC from CLH-2 eTWC measurements entails application of a sampling efficiency correction based on additional observations, including the background water vapor content, the wind field and particle size distributions. The resulting estimate of error in CWC will depend on the deployment conditions and measurement errors of the specific supporting instruments used in the sampling efficiency corrections; we estimate that CWC determination errors in these contributing measurements and the sampling efficiency calculations will yield a $1-\sigma$ uncertainty of $14.0 \%$ to $15.8 \%$ in CWC.
The total $1-\sigma$ estimated uncertainty (Table 1 ) in CWC observations produced using the CLH-2 is $14.3 \%$ to $16.1 \%$, including uncertainties in CLH-2 calibrations and in CWC determination.

\section{Initial airborne deployment}

The CLH-2 made total water measurements during the Deep Convective Clouds \& Chemistry (DC3) campaign, which was organized to investigate chemical transport and processing associated with convective storms at mid-latitude continental sites. During flights from 15 May to 30 June 2012, the CLH-2 was installed in a wing canister aboard the NSF/NCAR Gulfstream-V (GV), where it operated at ambient temperatures from $-66^{\circ} \mathrm{C}$ to $31^{\circ} \mathrm{C}$ and at altitudes up to $14400 \mathrm{~m}$ (about $47 \mathrm{kft}$ ). Measurements from the CLH-2 were available for $\sim 84 \%$ of research flight time. Based on the standard deviation of TWC measured during cloud-free periods, the precision of $1 \mathrm{~Hz}$ data is estimated to be $160 \mathrm{ppm}$. An example of CLH-2 flight data (Fig. 6) from DC3 shows measurements of CWC during a sequence of cloud intersections over the course of $15 \mathrm{~min}$. As an independent indicator of the presence of condensed water particles, also shown is the particle volume concentration observed with the Particle Measurement Systems 2D-C optical array probe (OAP-2DC; Gordon and Marwitz, 1984), with all particles assumed to be spherical. The observed spikes in particle volume concentration during cloud intersections are matched by corresponding spikes in CWC, suggesting that the CLH-2 indeed responds to the presence of cloud water particles. Although beyond the scope of this paper, detailed intercomparisons with other 


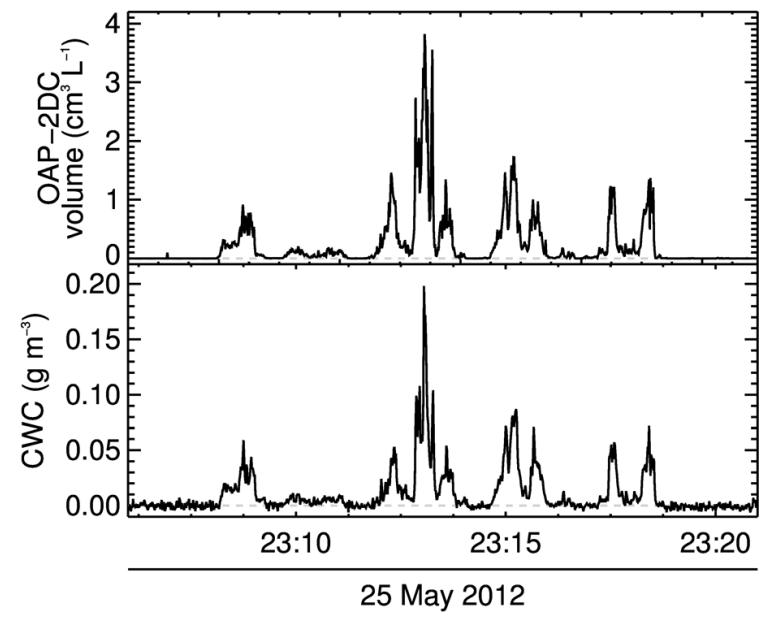

Fig. 6. Example of in-flight observations from a sequence of cloud intersections on 25 May 2012 during the DC3 campaign. Shown are (bottom) CWC based on CLH-2 measurements and (top) volume concentration of particles observed by the OAP-2DC, with particles assumed to be spherical.

cloud water instruments are planned. During the Instrument Development and Education in Airborne Science (IDEASIV) campaign in September and October 2013 concurrent measurements of CWC were made aboard the GV with the CLH-2 and the Counterflow Virtual Impactor (CVI; Twohy et al., 1997) cloud water instrument. Flow rates on the CVI inlet provide a control on the range of particle sizes that are sampled, and observations made at different counterflow rates during the campaign may yield information about the size dependency of the CLH-2 particle sampling efficiency, with implications for the resulting CLH-2 measurements of CWC.

\section{Conclusions}

We have described the measurement principles and design characteristics of a new total water instrument, the secondgeneration University of Colorado closed-path tunable-diode laser hygrometer, or CLH-2. Several design features will enable the CLH-2 to be used in a variety of environments. The mechanically isolated, thermally stabilized optical bench resists changes to optical path length or laser alignment due to vibration, impacts to the case and temperature variations. The instrument is designed to be mounted on an aircraft in a standard scientific aircraft wing canister, and has an integral, heated inlet. The use of fiber-coupled optics and a sealed, desiccated housing reduces water vapor in optical cavities without the need for dry purge gas that must be monitored and replenished regularly. The use of direct-absorption spectroscopy permits simplified electronics and data processing, but limits the useful application of the instrument to situations where the enhanced total water mixing ratio is $750 \mathrm{~mol} \mathrm{~mol}^{-1}$ or greater. Results from a numerical model show that only those spherical ice crystals smaller than $58 \mu \mathrm{m}$ will be completely vaporized in the CLH-2 inlet; however, collisions of particles at bends in the CLH-2 transfer lines will facilitate vaporization of larger particles. A vapor-only laboratory comparison shows the CLH-2 VMR to agree to within 2- $\sigma$ uncertainty bounds with the VMR reported by the first-generation CLH. The 1- $\sigma$ expected uncertainty in CWC determined using the CLH-2 and supporting measurements is $14.3 \%$ to $16.1 \%$. Future in-cloud comparisons with other instruments designed to measure condensed water will help to further characterize the CLH-2 instrument and reduce the uncertainties in parameters used to define the enhancement factor, which is the single largest source of error in CWC calculations.

Acknowledgements. The Deep Convective Clouds \& Chemistry Experiment (DC3) is sponsored by the National Science Foundation (NSF), the National Aeronautics and Space Administration, the National Oceanic and Atmospheric Administration, and the Deutsches Zentrum fur Luft- und Raumfahrt. The authors would like to thank the DC3 science and support teams and the NSF/NCAR GV flight and ground personnel. This material is based upon work supported by the National Science Foundation under grant no. 0964238 and by the National Science Foundation Graduate Research Fellowship Program under grant no. 1144083. Any opinions, findings, and conclusions or recommendations expressed in this material are those of the authors and do not necessarily reflect the views of the National Science Foundation.

Edited by: S. Malinowski

\section{References}

Allan, R. P.: Combining satellite data and models to estimate cloud radiative effect at the surface and in the atmosphere, Meteorol. Appl., 18, 324-333, 2011.

Arroyo, M. and Hanson, R.: Absorption-measurements of watervapor concentration, temperature, and line-shape parameters using a tunable InGaAsP diode-laser, Appl. Optics, 32, 6104-6116, 1993.

Baumgardner, D., Brenguier, J. L., Bucholtz, A., Coe, H., DeMott, P. J., Garrett, T. J., Gayet, J.-F., Hermann, M., Heymsfield, A. J., Korolev, A. V., Kraemer, M., Petzold, A., Strapp, J. W., Pilewskie, P., Taylor, J., Twohy, C. H., Wendisch, M., Bachalo, W., and Chuang, P.: Airborne instruments to measure atmospheric aerosol particles, clouds and radiation: A cook's tour of mature and emerging technology, Atmos. Res., 102, 1029, 2011.

Baumgardner, D., Avallone, L. M., Bansemer, A., Borrmann, S., Brown, P., Bundke, U., Chuang, P. Y., Cziczo, D., Field, P., Gallagher, M., Gayet, J.-F., Heymsfield, A., Korolev, A. V., Kraemer, M., McFarquhar, G., Mertes, S., Moehler, O., Lance, S., Lawson, P., Petters, M. D., Pratt, K., Roberts, G., Rogers, D., Stetzer, O., Stith, J., Strapp, J. W., Twohy, C. H., and Wendisch, M.: In situ, airborne instrumentation: Addressing and solving measurement problems in ice clouds, Bull. Am. Meteorol. Soc., 93, E529-E534, 2012. 
Boudala, F. S., Isaac, G. A., Cober, S. G., and Fu, Q.: Liquid fraction in stratiform mixed-phase clouds from in situ observations, Q. J. Roy. Meteor. Soc., 130, 2919-2931, 2004.

Brown, P. and Francis, P.: Improved measurements of the ice watercontent in cirrus using a total-water probe, J. Atmos. Ocean. Tech., 12, 410-414, 1995.

Cober, S. G., Isaac, G. A., Korolev, A. V., and Strapp, J. W.: Assessing cloud-phase conditions, J. Appl. Meteorol., 40, 1967-1983, 2001.

Davis, S. M., Avallone, L. M., Weinstock, E. M., Twohy, C. H., Smith, J. B., and Kok, G. L.: Comparisons of in situ measurements of cirrus cloud ice water content, J. Geophys. Res.-Atmos., 112, D10212, doi:10.1029/2006JD008214, 2007a.

Davis, S. M., Hallar, A. G., Avallone, L. M., and Engblom, W.: Measurement of total water with a tunable diode laser hygrometer: Inlet analysis, calibration procedure, and ice water content determination, J. Atmos. Ocean. Tech., 24, 463-475, $2007 \mathrm{~b}$.

Durham, M. and Lundgren, D.: Evaluation of aerosol aspiration efficiency as a function of Stokes number, velocity ratio and nozzle angle, J. Aerosol. Sci., 11, 179-188, 1980.

Engblom, W. and Ross, M.: Numerical model of airflow induced particle enhancement for instruments carried by the WB-57F aircraft, ATR-2004(5084)-1, The Aerospace Corporation, El Segundo, CA, USA, 2003.

Gordon, G. L. and Marwitz, J. D.: An airborne comparison of three PMS probes, J. Atmos. Ocean. Tech., 1, 22-27, 1984.

Gultepe, I. and Isaac, G. A.: Liquid water content and temperature relationship from aircraft observations and its applicability to GCMs, J. Climate, 10, 446-452, 1997.

Hallar, A. G., Avallone, L. M., Herman, R., Anderson, B., and Heymsfield, A. J.: Measurements of ice water content in tropopause region arctic cirrus during the SAGE III Ozone Loss and Validation Experiment (SOLVE), J. Geophys. Res.-Atmos., 109, D17203, doi:10.1029/2003JD004348, 2004.

Held, I. and Soden, B. J.: Water vapor feedback and global warming, Annu. Rev. Energ. Env., 25, 441-475, 2000.

Hogan, R. J., Field, P. R., Illingworth, A. J., Cotton, R. J., and Choularton, T. W.: Properties of embedded convection in warmfrontal mixed-phase cloud from aircraft and polarimetric radar, Q. J. Roy. Meteor. Soc., 128, 451-476, 2002.

Khelif, D., Burns, S., and Friehe, C.: Improved wind measurements on research aircraft, J. Atmos. Ocean. Tech., 16, 860-875, 1999.

Korolev, A. V., Strapp, J. W., Isaac, G. A., and Nevzorov, A.: The Nevzorov airborne hot-wire LWC-TWC probe: Principle of operation and performance characteristics, J. Atmos. Ocean. Tech., 15, 1495-1510, 1998.

Korolev, A. V., Isaac, G. A., Cober, S. G., Strapp, J. W., and Hallett, J.: Microphysical characterization of mixed-phase clouds, Q. J. Roy. Meteor. Soc., 129, 39-65, 2003.

Korolev, A. V., Strapp, J. W., Isaac, G. A., and Emery, E.: Improved Airborne Hot-Wire Measurements of Ice Water Content in Clouds, J. Atmos. Ocean. Tech., 30, 2121-2131, doi:10.1175/JTECH-D-13-00007.1, 2013.
Li-Cor: LI-610 Portable Dew Point Generator Operating and Service Manual, Lincoln, Nebraska, 2004.

Liou, K.: Radiation and Cloud Processes in the Atmosphere: Theory, Observation, and Modeling, Oxford University Press, New York, 1992.

Magono, C. and Lee, C.: Meteorological classification of natural snow crystals, J. Fac. Sci. Hokkaido U, Ser. VII, 2, 321-362, 1966.

May, R. D. and Webster, C. R.: Data processing and calibration for tunable diode laser harmonic absorption spectrometers, J. Quant. Spectrosc. Ra., 49, 335-347, 1993.

Podolske, J. R., Sachse, G. W., and Diskin, G. S.: Calibration and data retrieval algorithms for the NASA Langley/Ames Diode Laser Hygrometer for the NASA Transport and Chemical Evolution Over the Pacific (TRACE-P) mission, J. Geophys. Res.Atmos., 108, 8792, doi:10.1029/2002JD003156, 2003.

Rothman, L. S., Jacquemart, D., Barbe, A., Benner, D., Birk, M., Brown, L., Carleer, M., Chackerian, C., Chance, K., Coudert, L., Dana, V., Devi, V., Flaud, J., Gamache, R. R., Goldman, A., Hartmann, J., Jucks, K., Maki, A., Mandin, J., Massie, S., Orphal, J., Perrin, A., Rinsland, C., Smith, M., Tennyson, J., Tolchenov, R., Toth, R., Vander Auwera, J., Varanasi, P., and Wagner, G.: The HITRAN 2004 molecular spectroscopic database, J. Quant. Spectrosc. Ra., 96, 139-204, 2005.

Stephens, G.: Cloud feedbacks in the climate system: A critical review, J. Climate, 18, 237-273, 2005.

Strapp, J. W., Oldenburg, J., Ide, R., Lilie, L. E., Bacic, S., Vukovic, Z., Oleskiw, M., Miller, D., Emery, E. F., and Leone, G.: Wind tunnel measurements of the response of hot-wire liquid water content instruments to large droplets, J. Atmos. Ocean. Tech., 20, 791-806, 2003.

Strom, J. and Heintzenberg, J.: Water-vapor, condensed water, and crystal concentration in orographically influenced cirrus clouds, J. Atmos. Sci., 51, 2368-2383, 1994.

Twohy, C. H., Schanot, A., and Cooper, W.: Measurement of condensed water content in liquid and ice clouds using an airborne counterflow virtual impactor, J. Atmos. Ocean. Tech., 14, 197202, 1997.

Weinstock, E. M., Smith, J. B., Sayres, D., Pittman, J. V., Allen, N., and Anderson, J. G.: Measurements of the total water content of cirrus clouds. Part II: Instrument performance and validation, J. Atmos. Ocean. Tech., 23, 1410-1421, 2006.

Wood, R. and Field, P. R.: Relationships between total water, condensed water, and cloud fraction in stratiform clouds examined using aircraft data, J. Atmos. Sci., 57, 1888-1905, 2000.

Zondlo, M. A., Paige, M. E., Massick, S. M., and Silver, J. A.: Vertical cavity laser hygrometer for the National Science Foundation Gulfstream-V aircraft, J. Geophys. Res.-Atmos., 115, D20309, doi:10.1029/2010JD014445, 2010. 